
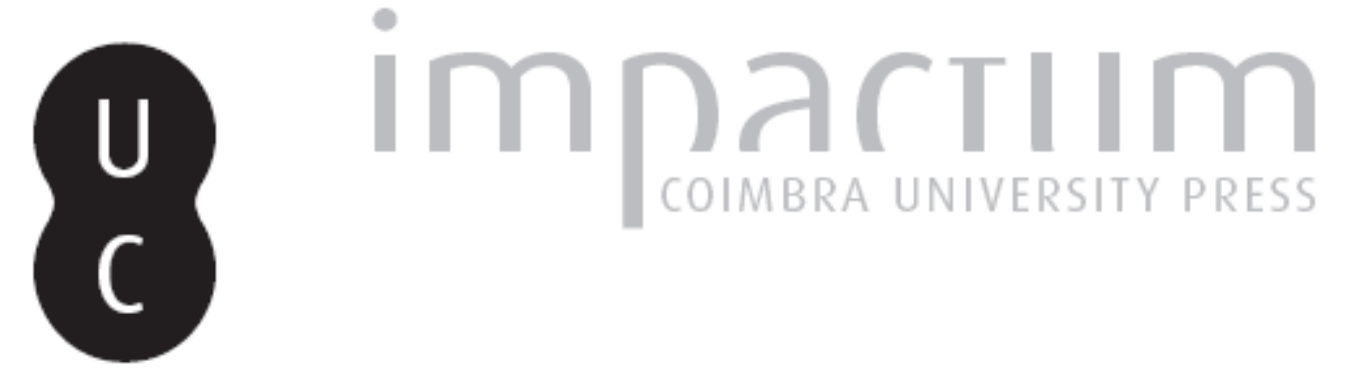

\title{
A Casa da Livraria da Universidade de Coimbra ao tempo de D. João V
}

Autor(es): $\quad$ Ferrão, Pedro Miguel

Publicado por: Imprensa da Universidade de Coimbra

URL persistente:

URI:http://hdl.handle.net/10316.2/42751

DOI:

DOI:https://doi.org/10.14195/1647-8436_46_47_4

Accessed : $\quad$ 26-Apr-2023 01:14:53

A navegação consulta e descarregamento dos títulos inseridos nas Bibliotecas Digitais UC Digitalis, UC Pombalina e UC Impactum, pressupõem a aceitação plena e sem reservas dos Termos e Condições de Uso destas Bibliotecas Digitais, disponíveis em https://digitalis.uc.pt/pt-pt/termos.

Conforme exposto nos referidos Termos e Condições de Uso, o descarregamento de títulos de acesso restrito requer uma licença válida de autorização devendo o utilizador aceder ao(s) documento(s) a partir de um endereço de IP da instituição detentora da supramencionada licença.

Ao utilizador é apenas permitido o descarregamento para uso pessoal, pelo que o emprego do(s) título(s) descarregado(s) para outro fim, designadamente comercial, carece de autorização do respetivo autor ou editor da obra.

Na medida em que todas as obras da UC Digitalis se encontram protegidas pelo Código do Direito de Autor e Direitos Conexos e demais legislação aplicável, toda a cópia, parcial ou total, deste documento, nos casos em que é legalmente admitida, deverá conter ou fazer-se acompanhar por este aviso.

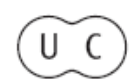




\section{BOLETIM DA \\ BIBLIOTECA GERAL DA UNIVERSIDADE DE COIMBRA}

VOL. 46/47 (2015/2016)

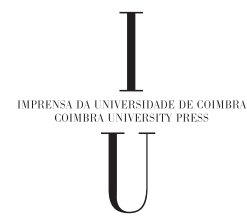




\section{A Casa da Livraria da Universidade de Coimbra ao tempo de D. João V}

Pedro Miguel Ferrão'

\section{RESUMO}

A biblioteca universitária conimbricense seria transferida para um novo edifício, construído de raiz entre 1717 e 1728, por iniciativa do rei D. João V. Este elegante projecto arquitectónico seria transfigurado no seu interior com uma das mais sumptuosas e eloquentes decorações barrocas em talha dourada, enriquecida pela representação de chinoiseries e ainda pelas pintura dos seus tectos em trompe l'oeil, a qual se tornaria, segundo palavras do erudito conde Raczinski, la bibliothèque la plus richement ornée que j'aie jamais visitée.

Com efeito, na Casa da Livraria reside, de forma indelével, o espírito da esclarecida acção mecenática do Magnânimo - consagrada mais tarde na nomenclatura adoptada que a passará a designar por Biblioteca Joanina -, lugar privilegiado em que Arte, Cultura e Ciência se conjugam em perfeita harmonia. Autêntico Palácio do Saber, o seu aparatoso cenário traduz uma autêntica cosmovisão do Homem e da Cultura Barroca do séc. XVIII.

\section{PALAVRAS-CHAVE}

Barroco; Biblioteca; Chinoiseries; D. João V; Trompe I'oeil; Universidade de Coimbra; Biblioteca Joanina.

\section{ABSTRACT}

The library of the University of Coimbra was transferred to a new building constructed under the reign of D. João V, between 1717 and 1728 . This ele-

1 Conservador do Museu Nacional de Machado de Castro - pedroferrao@mnmc. dgpc.pt 
gant architectural project was provided in its interior with one of the most sumptuous and eloquent baroque decorations in gilded carving, enriched by the representation of Chinoiseries and by the painting of its ceilings in trompe l'oeil, becoming, per the scholar Count Raczinski, la bibliothèque la plus richement ornée que j'aie jamais visitée.

Indeed, the Library House holds indelibly the spirit of the enlightened patronage of the Magnânimo - its name was later consecrated in the adopted nomenclature as the Joanina Library -, being a privileged place where Art, Culture and Science combine themselves in perfect harmony. An authentic Palace of Wisdom, its spectacular scenery translates into an authentic cosmos vision of Man and the Baroque Culture of the 18th century.

\section{KEYWORDS}

Baroque; Library; Chinoiseries; D. João V; Trompe l'oeil; University of Coimbra. Joanina Library.

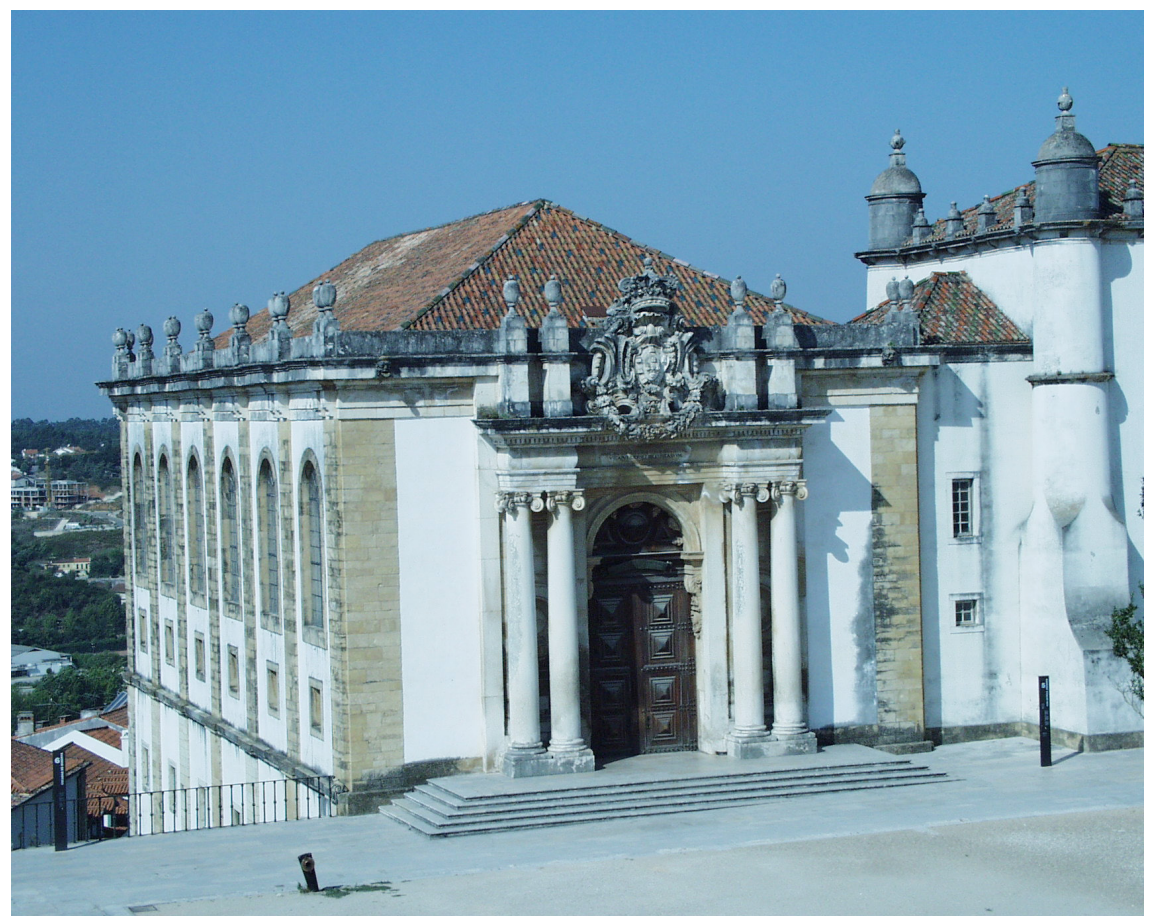

Fachada da Biblioteca Joanina 


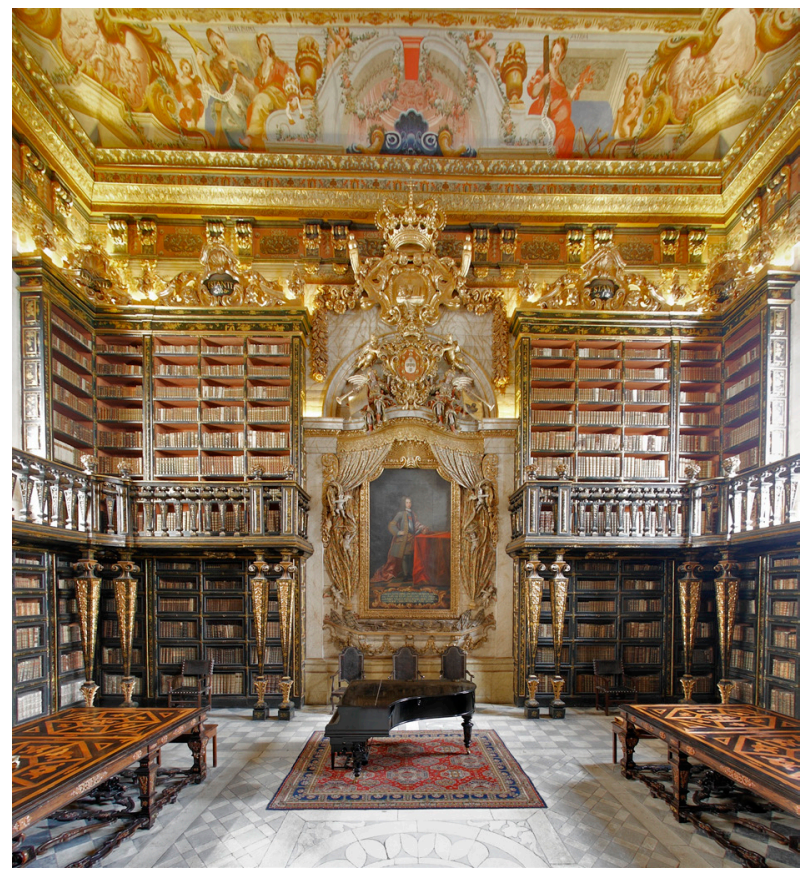

Interior da Biblioteca Joanina

No séc. XVIII, a biblioteca universitária conimbricense seria transferida para um novo edifício, construído de raíz por iniciativa de D. João V. Vários foram os motivos que contribuíram para a renovação da Casa da Livraria. Desde logo, as obras de remodelação da ala escolar dos Gerais - projectadas nos finais do séc. XVII e concluídas nos começos do século seguinte, por iniciativa do Reitor D. Nuno da Silva Teles I - adicionaram novos problemas ao espaço que Ihe tinha sido destinado. Com efeito, os fundos bibliográficos encontravam-se acondicionados numa sala situada no átrio dos Gerais, como se pode ainda confirmar pelo medalhão que ostenta sobre o portal. Ao mexer na antiga construção arquitectónica, afectaram parte da estrutura desta sala, obrigando à transferência em 1705 dos livros para o piso superior, onde se encontrava localizado o cartório.

Esta situação tornou-se insustentável, pelo que, em 1716, o novo reitor - D. Nuno da Silva Teles, o segundo deste nome - redige uma 
carta a D. João V esclarecendo que a Universidade não possuía instalações condignas para albergar os fundos bibliográficos, como determinavam os seus estatutos, pedindo que autorizasse a procurar um local adequado para realizar obras de adaptação. A resposta do monarca - enviada a 31 de Outubro desse mesmo ano - confirma não só as pretensões do reitor, como autoriza ainda a construção de um edifício próprio no espaço universitário. Ao mesmo tempo, a missiva real ordena a compra da biblioteca pessoal do Dr. Francisco Barreto, enriquecendo, deste modo, o seu acervo bibliográfico.

Assim, o plano de requalificação encontra-se em desenvolvimento e passa agora por encontrar uma nova área no recinto universitário. A escolha recairá numa parcela contígua à Capela de S. Miguel, local onde se encontravam as ruínas do antigo cárcere palatino de finais do séc. XIV, ao tempo de D. João I. Trata-se de um terreno desnivelado que prolongará o anterior terreiro universitário.

Preparado o terreno alguns meses antes, o arranque da obra acontece, na presença do reitor, no dia 17 de Julho de 1717, concluída apenas em 1728. Durante os onze anos em que decorrerá este empreendimento, mestres-de-obras, canteiros, entalhadores, pintores, latoeiros, carpinteiros, marceneiros, vidraceiros e outros artífices vão conferindo forma a um projecto que se consubstancia numa das mais sumptuosas e elegantes arquitecturas do período barroco, e que seria, segundo palavras do erudito conde Raczinski, la bibliothèque la plus richement ornée que j'aie jamais visitée.

Um dos enigmas que o edifício encerra reporta-se ao nome do arquitecto que o projectou. De facto, os documentos remanescentes são extremamente minuciosos sobre contratos, pagamentos e outras incidências da obra, mas totalmente omissos quanto a esta questão, revelando apenas o nome de João Carvalho Ferreira, mestre-de-obras da Universidade, que seria substituído por Gaspar Ferreira empreiteiro contratado inicialmente para a realização das estantes - devido a dificuldades na interpretação da planta e na supervisão 
da obra. É provável que o autor do projecto seja o escultor francês Claude Laprade, tendo em consideração as semelhanças formais da disposição interior da biblioteca com a sua obra escultórica deixada nos Gerais (entre 1699-1702), assim como o trabalho das estantes com algumas estruturas retabulares executadas no mesmo período para igrejas da capital.

Delineada tendo em consideração o desnível do terreno em que se implanta - com o acesso exterior sul a ser efectuado pelas escadas de Minerva, uma obra construída a partir de 1724 por Gaspar Ferreira - a Casa da Livraria projecta um sóbrio e sólido paralelepípedo, dividido em três andares. O primeiro integra as preexistências do séc. XIV com a função de depósito, enquanto o intermédio se destinava a albergar os gabinetes dos docentes, ao mesmo tempo que cumpria a função de suporte do andar nobre. Este abria-se sobre o pátio universitário, projectado para acondicionar o espólio bibliográfico e para a sua consulta pública.

A fachada sul é animada por duas séries de seis janelas pequenas de vão quadrangular, ao nível do piso intermédio e superior, sobrepujadas por igual número de altas janelas com arco de volta perfeita. São rematadas por saliente cornija misulada e coroadas por pares de urnas ovadas. A face oeste é rasgada por três janelas cegas de vão semi-circular, tendo outras mais pequenas e de formato rectangular no seu alinhamento vertical. A fachada virada a norte é formada por quatro janelas e mantém-se original, dado que as restantes fachadas e vãos das janelas foram delimitadas com pedra lioz, numa intervenção efectuada na $1^{a}$ metade do séc. XX pela Direcção Geral dos Edifícios e Monumentos Nacionais, subvertendo a leitura inicial do edifício.

$\mathrm{Na}$ fachada principal sobressai o imponente portal traçando um arco de triunfo, apoiado em mísulas terminais bastante decoradas, e ladeado por dupla e grandiosa colunata jónica, sobrepujado pelo volumoso brasão de armas de D. João V. Aqui se inicia o percurso de um eloquente discurso produzido por esta biblioteca-falante, singu- 
lar e coerente programa de arte, ciência e cultura. Como manifesto disso gravaram-se, ao nível do entablamento, os seguintes caracteres latinos: Hanc avgvsta dedit libris collimbria sedem, vt capvt exornet bibliotheca svvm ("Esta é a sede que a Augusta Coimbra deu aos livros, para que a biblioteca lhe coroe a fronte"). A porta de madeira ostenta uma tarja em latão com uma inscrição latina: Lvsiadae, hanc vobis sapientia condiditarcem: dvctores libri; miles et arma labor ("Lusos, este é o caminho que vos aponta a sabedoria: por capitães os livros; por soldados e armas o trabalho").

Palavra e imagem integram-se e reforçam-se de uma forma ainda mais visível no sumptuoso ambiente interior da biblioteca. A unidade do espaço é-lhe conferida pela inteligente articulação entre as suas distintas partes, estabelecida por diferentes desenhos dos pavimentos em pedra; pela grandiosa estrutura e decoração das estantes - elegante obra de chinoiserie concebida em quarenta meses (1723-27) pelo pintor Manuel da Silva, reproduzindo exóticas paisagens ao gosto oriental; das pinturas em trompe l'oeil dos tectos, encomendadas em 1723 à dupla lisboeta Vicente Nunes e António Simões Ribeiro, ou ainda pela sobrecarga de outros ornamentos em talha dourada e pelo mobiliário, como os seis bufetes de leitura executados, entre 1725-27, em preciosas e exóticas madeiras brasileiras pelo italiano Francesco Realdino.

O esquema do interior é simples: um comprido rectângulo subdividido em três salas rectangulares que comunicam entre si através de arcos de volta perfeita, repetindo a composição do portal nobre. Esta sequência de arcos comunicantes vai traçar uma linha axial que nos conduz até à última sala, dirigida ao retrato de $\mathrm{D}$. João $\mathrm{V}$, pintura atribuída a Domenico Duprá (cerca de 1725).

No interior da porta de entrada nova tarja em latão remete para o código discursivo e imagético da biblioteca, afirmando que Pandvtvr cvntis excvlta palatia libris: hvc ades; avtores consvle, doctvs eris. Haec tibi pro stvdiis et lex et norma teneta est: mens legat, obsevet sedvla; 
penna notet ("A todos se franqueiam estes palácios, de livros adornados. Entra aqui, consulta os autores e serás douto. No teu estudo, esta lei e norma deve ser observada: a mente leia, medite com zelo, a pena anote").

Com a notação de cor verde e dedicada aos cursos de Medicina e de Matemática, de acordo com as insígnias que ostentam os medalhões sobre as portas, o ambiente da primeira sala prossegue o discurso simbólico nas pinturas que se acomodam nos tectos e nas sancas. Ao centro preside a figura da Sabedoria sob a forma de uma formosa mulher, representando aqui a própria Biblioteca (autenticada pela inscrição Biblioteca Imago) rodeada de pequenos anjos, com a legenda Felices ornent haec instrumenta libellos ("Estas estantes ornam os livrinhos, felizes"), ao mesmo tempo que recebe o conhecimento dos quatro continentes da Terra, representados pelas alegorias de África, Ásia, Europa e América.

A sala seguinte, com as estantes de cor vermelha e consagrada às faculdades de Cânones e de Leis, é preenchida no tecto com a imagem da própria Universidade (com a legenda Universitas), novamente rodeada de putti que transportam outra tarja, reproduzindo um verso das Éclogas de Virgílio: Clavdite iam rivos pverti sat, prata bibervnt ("Fechai, meninos, as regas, que os prados já beberam bastante"). Na sanca aparecem alegorias que personificam as qualidades que se devem possuir para alcançar a sabedoria: honra, virtude, fortuna e fama. Nos medalhões representam-se efígies de poetas latinos: Virgílio, Ovídio, Séneca e Cícero, uma consagração da imortal cultura clássica.

Finalmente, na última sala - de cor negra e marcada pelos símbolos universitários da Teologia e da Retórica (Artes) -, o tecto retrata a própria Sapiência (com a legenda Enciclopedia) recebendo a síntese do saber transmitido pelos diversos cursos universitários, pois só com estas fontes de conhecimento poderemos alcançar as verdades do mundo. Essa mensagem é reforçada por um excerto retirado da 
Eneida de Virgílio: Dabitvr tellvris operta svbire avricomos siqvis de cerpserit arbot fetvs virg aened ("Só é permitido penetrar nas secretas entranhas da terra, se alguém colher da árvore os ramos de ouro").

Assim, cada alegoria universitária feminina aparece, uma vez mais, na sanca do tecto: a Sacra Pagina representa a Teologia e os Cânones, mostrando a seguinte legenda: En nobis theologiam et cannones ad domvs ("Aqui temos a Teologia e Cânones na sua morada"); Astraea, figurada pelas Leis com uma fita onde se inscreve a citação de Séneca: Caelestivm terra astraea relinqvit ("A Justiça deixou a morada dos deuses pela terra"); a Natura (Ciências da Natureza) explicitada por dois letreiros, o primeiro, retirado dos Remedia Amoris, e aludindo à Medicina, Temporibvs medicina valet ("A Medicina permanece ao longo dos tempos"); a outra, referência à Matemática e à Filosofia, Mathematica et Philosophia caelvm et terram circvivi sola ("Com a Matemática e a Filosofia, apenas, percorri céus e terra"). Por fim, alude-se a Ars (Artes), com as palavras Omnes grammaticos q rhetoras q moneo ("Exorto todos os gramáticos e retóricos"), e Música, onde uma fita mostra a legenda Musica obletat et allicit ("A música deleita e seduz").

Contudo, a apoteose desta relação dialéctica é alcançada pelo discurso de elogio ao rei, que se inscreve numa cartela sob a elaborada estrutura cenográfica do retrato de $D$. João V:

Regia, qvam cernis, specvlvm tibi praestat imago: in specvlo totvm, qvod capit avla, vides.

Qvae qve avgvsta patent, ioannes ordine qvintvs condidit, aeternvm principe vivat opvs.

("O retrato régio que contemplas está na tua frente como um espelho: nesse espelho vês tudo o que este palácio contém. E tudo o que de majestoso ostenta realizou-o João Quinto. Viva eterna a obra juntamente com o príncipe").

O impacto das imagens sai reforçado pela presença dos vários discursos em latim, traduzindo e ampliando a experiência sensorial e racional, que, a cada momento, se revela na morada da sabedoria. 
Com efeito, na Casa da Livraria reside, de forma indelével, o espírito da esclarecida acção mecenática de D. João V - consagrado mais tarde na nomenclatura adoptada que a passará a designar por Biblioteca Joanina -, lugar privilegiado em que a Arte, Cultura e Ciência se conjugam em perfeita harmonia. Autêntico Palácio do Saber, o seu aparatoso cenário traduz uma certa cosmovisão do Homem e da Cultura Barroca do séc. XVIII.

\section{Bibliografia}

ALMEIDA, Manuel Lopes de - Artes e Ofícios em documentos da Universidade : Séc. XVIII (1701-1726). Coimbra : Imprensa da Universidade, 1971.

ALMEIDA, Manuel Lopes de - Artes e Ofícios em documentos da Universidade : Séc. XVIII (1726-1753). Coimbra : Imprensa da Universidade, 1974.

AMARAL, A. E. Maia do, coord. - Os livros em sua ordem : para a história da Biblioteca Geral da Universidade (antes de 1513-2013). Coimbra : Imprensa da Universidade de Coimbra, 2014. ISBN 978-989-26-0893-8.

BANDEIRA, José Ramos - Universidade de Coimbra. Edifícios do Corpo Central e Casa dos Melos. Coimbra : Casa do Castelo Editora, 1943. vol. 1.

BORGES, Nelson Correia - Do Barroco ao Rococó. In Historia da Arte em Portugal. Lisboa : Publicações Alfa, 1986. vol. 9.

CARVALHO, A. Ayres de - D. João V e a Arte do seu Tempo. Mafra, 1960-1962. 2 vol.

CASTRO, Aníbal Pinto de - A Livraria da Universidade. Historia da Universidade em Portugal. Coimbra : Universidade de Coimbra ; Lisboa : Fundação Calouste Gulbenkian, 1997. vol. 2 (1537-1771).

FERRÃO, Pedro - A construção da Casa da Livraria da Universidade de Coimbra. Actas do Colóquio A Universidade e a Arte. 1290-1990 [separata]. Coimbra : Instituto de Historia da Arte da Faculdade de Letras da Universidade de Coimbra, 1993.

FEYO, Florêncio Mago Barreto - Memoria Histórica e Descriptiva acerca da Biblioteca da Universidade de Coimbra. Coimbra : Imprensa da Universidade, 1857.

FIGUEIREDO, A. C. Borges de - Coimbra Antiga e Moderna. Lisboa, 1886.

GONÇALVES, A. Nogueira ; CORREIA, Vergílio - Inventario Artístico de Portugal. Cidade de Coimbra. Lisboa : Academia Nacional de Belas Artes, 1947.

MADAHIL, A. da Rocha - Biblioteca da Universidade de Coimbra. Grande Enciclopédia Portuguesa-Brasileira. Lisboa/Rio de Janeiro : Editorial Enciclopédia, [s/d]. vol. 4. 
PIMENTEL, António Filipe - O gosto oriental na obra das estantes da Casa da Livraria da Universidade de Coimbra. Portugal e Espanha entre a Europa e Além-mar. Coimbra : Instituto de Historia da Arte/Faculdade de Letras da Universidade de Coimbra, 1988.

PIMENTEL, António Filipe - Bibliotecas. Dicionário da Arte Barroca em Portugal. Lisboa : Editorial Presença, 1989.

PIMENTEL, António Filipe - Uma empresa esclarecida: a Biblioteca Joanina. Revista Monumentos. Lisboa : Direcção Geral de Edifícios e Monumentos Nacionais. No 8 (Mar. 1998).

PIMENTEL, António Filipe - A Biblioteca da Universidade e os seus espaços. Tesouros da Biblioteca Geral da Universidade de Coimbra. Coimbra : Imprensa da Universidade de Coimbra, 2009.

SMITH, Robert C. - A Talha em Portugal. Lisboa : Livros Horizonte, 1962.

TEIXEIRA, António José - A Livraria da Universidade. O Instituto. Coimbra. S. 2, vol. 37 (1890).

\section{Fontes Manuscritas}

Arquivo da Universidade de Coimbra [A.U.C]:

Obras. Construção da Biblioteca Joanina, Caixas 13 a16 [A.U.C. - Dep. IV, S. 1aE., Est. 1, Tab. 1]

Obras. Construção da Biblioteca Joanina. Caixas 1 a 5 [A.U.C. - Dep. IV, S. 1aE., Est. 1, Tab. 2]

Obras. Construção da Biblioteca Joanina. Registo da Receita e Despesa. Vols. 8 a 16 [A.U.C. - Dep. IV, S. 1aE., Est. 1, Tab. 2]

Receita e Despesa, anos de 1716-1728, Livros 21 a 24 [A.U.C. - Dep. IV, S. 1aE., Est. 12, Tab. 3]

\section{Sites}

http://www.bibliotecajoanina.uc.pt 